\section{Japan sees gold in warming}

\section{Tokyo}

WHEN it comes to developing new technology that has a prospect of selling well, Japanese industry shows no lack of enthusiasm for saving the global environment. According to figures released this week, more than 60 major companies and economic organizations have now agreed to contribute a total of $¥ 50,000$ million ( $\$ 400$ million) for the establishment of a new research institute for "environmentfriendly technology" at Kansai science city, located close to Osaka, Kyoto and Nara.

The Research Institute of Innovative Technology for the Earth (RITE) is being established under the jurisdiction of the Ministry of International Trade and Industry (MITI) which is pouring over $¥ 70,000$ million a year into the research and development of substitute chlorofluorocarbons, biogradable plastics, and technology to reduce carbon dioxide emissions or to absorb and utilize the gas. In addition to the money from MITI and industry, local prefectural and municipal governments will inject another $¥ 30,000$ million into RITE making the institute probably the best-funded national project ever in Japanese history.

RITE is due to open in 1992 on a plot of land provided free by Kyoto Prefectural government. In addition to providing $¥ 17,000$ million of the $¥ 30,0000$ million in local government funding for RITE, the Kyoto prefectural government will also level the site for RITE, which is located in a steep valley, free of charge.

According to a list provide by Tsutomu Yamaguchi, senior managing director of RITE, 60 major companies covering almost the whole range of industry will be contributing money and researchers to the new institute. The particpants include electronic companies such as NEC, Toshiba, Sharp, Hitachi, Sanyo and Mitsubishi Electric; the steel manufacturing companies Nippon Steel, Kobe Steel and Nippon Kokan; heavy industries such as Kawasaki Heavy Industries, Ishikawajima Heavy Industries and Hitachi Zosen, a shipbuilding company; chemical companies like Takeda Chemical Industries; the car manufacturers Toyota and Nissan; electric power companies; gas companies; and even banks, trading companies, insurance companies, and Japan's leading manufacturer of women's underwear, Wacoal.

Many of the companies involved are from the Kansai area and particularly prominent is the Sumitomo group, including Sumitomo Metal Industries, Sumitomo Marine and Fire Insurance Co., Sumitomo Chemical Co., Sumitomo Bank, Sumitomo Heavy Industries, Sumitomo Electric Industries and Sumitomo institute. SOUTH AFRICAN EDUCATION

\section{Cape Town} realism in white communities. them with a set of complicated options. with whites-only status. HUMAN FRONTIERS
Life Insurance Co. Keidanren and Kansai Economic Federation will also support the

According to Yamaguchi, over 200 company researchers are already engaged in joint research with MITI's national laboratories and 80 researchers will be

\section{Voters' clear message on segregation}

PARENTs at two all-white high schools last week voted overwhelmingly in favour of opening the schools to all races. This is the first of many such polls to be held in South Africa in the next two months. That both schools are located in Uitenhage, an industrial town represented in parliament by a member of the Conservative Party, suggests the emergence of a new sense of

The government is faced with over 300,000 empty places at white schools, and an estimated 1 million black children with no schools to attend. Reluctant to open white schools at all, the government has passed the buck to the parents, presenting

The first two options are to be 'privatized' (in which case the state pays the school a 45 per cent subsidy) and 'state-aided' (with the state paying a 75 per cent subsidy). In both cases, the school can determine its own admissions policy. The third option is to remain fully state-controlled and financed, either with open status (but with whites being given priority for places) or

The first two options both require the approval of 72 per cent of a poll of at least

\section{The taxman's human face}

\section{Tokyo}

THANKS to the Ministry of Finance, Japan has managed to find a way around the strange rules that forced Japanese recipients of grants from Japan's own Human Frontier Science Program to return half of their grants in tax. The problem began because the programme set up its headquarters in Strasbourg, meaning Japanese universities were forced to classify Frontier grants as 'foreign funds', even though most of the money originally came from their own government.

In April, when the first grants for research on the brain and molecular biology were given out, Japanese recipients were dismayed to discover that Ministry of Education, Science and Culture (MESC) regulations prohibited universities and other MESC-affiliated research organizations from receiving these 'foreign funds' directly. Instead, the researchers had to assigned to RITE when it opens in 1992. Yukinori Fujiwara of the Kansai Economic Federation says that, although banks, trading companies and insurance companies will not be directly involved in the research, they have joined because they realize that the global environment probthe whole of Japanese industry.

David Swinbanks lem and measures to combat it will affect

80 per cent of the parents, as does the third option if the school wishes to become open; only schools not wishing to do so are absolved from holding referenda. Even so, the final decision on the fate of each school lies with the Minister of Education and Culture, Piet Clase, and the poll results are merely intended to guide him in making decisions. This process should keep even his vast army of bureaucrats busy for many months to come.

Clase's plan cannot solve all the problems of the educational system because it does not address the severe shortage of teachers, particularly in science and mathematics. Last year in white secondary schools (which received the highest level of per capita funding), 36 per cent of physical science posts, 32 per cent of mathematics posts and 21 per cent of biology posts were occupied by persons with either no, or only one year of, university education in their subject.

Nor is there much hope for future recruitment of teachers. In 1988 South Africa's twenty-one universities produced only 223 mathematics, 176 chemistry and 102 physics majors between them, and only a fraction of them are likely to enter the teaching profession. Michael Cherry

receive the money themselves and then 'donate' it to the university. But that meant the grants were treated as 'personal income' and subject to $40-50$ per cent income tax.

Officials of the Science and Technology Agency (STA) and Ministry of International Trade and Industry (MITI) tried to solve the problem by asking MESC to change university regulations. But MESC refused to cooperate because, as one MITI official put it, "they want to keep strict control over the universities".

MITI and STA then turned to the Ministry of Finance which last week gave the Frontier grants special tax-exempt status.

"Extensive efforts" and "vigorous" persuasion were needed, but in the end the "Japanese taxmen are finally found to be generous", says Ryuji Shimoda, director of STA's Frontier office.

David Swinbanks 